\title{
Hazar Bölgesinde Rusya ve AB Ekonomi-Politik Çekişmesi ve "Ukrayna” Faktörü
}

\author{
Emel PARLAR DAL ${ }^{*}$ \\ Ali Murat KURŞUN**
}

\begin{abstract}
Öz
Uluslararası çatışmaların merkezinde konumlanan Hazar bölgesi, uzun bir zamandır Rusya ve AB arasındaki jeopolitik ve enerji bağlantılı çıkarlar çerçevesinde şekillenen çekişmelere şahit olmaktadır. Rusya’nın eski Sovyet coğrafyasında yeniden etkisini oluşturma çabalarının ve AB’nin enerji güvenliğini ve çeşitliliğini Hazar bölgesi üzerinden arttırmaya yönelik uğraşlarının belirli bir şekilde bazı konularda çakıştı̆̆ı görülmektedir. Özellikle son gelişmeler ışığında Ukrayna krizi de bu denkleme yeni bir boyut katmış ve bu iki taraf arasındaki çekişmelerin daha da yoğunlaşmasına neden olmuştur. Bu çalışma Ukrayna krizine odaklanarak özellikle Rusya ve $\mathrm{AB}$ arasındaki bu ekonomi-politik çekişmesini ele almakta ve Rusya ve AB'nin yeni siyasi ve enerji projelerini geriye dönük şekilde detaylıca analiz ederek bu krizin bölgesel ve uluslararası etkilerini incelemektedir.
\end{abstract}

Anahtar Kelimeler: Rusya, Avrupa Birliği, Hazar bölgesi, boru hatları siyaseti, enerji güvenliği, Nabucco, TANAP, TAP, Avrasya Gümrük Birliği

\section{Politic-Economic Competition Between Russia and the EU in the Caspian Region:The "Ukranian" Factor}

\begin{abstract}
Caspian region located at the center of the international conflicts has long been witnessing the ongoing clashes between Russia's and the EU's geopolitical and energy related interests. Russian efforts in reexerting its influence in the ex-geography of the Soviet Union and the EU's efforts in increasing its energy security and diversity in the Caspian region seem to be overlapping in some issue related areas. The recent Ukrainian crisis has been newly added to this equilibrium and has also contributed to the increasing clashes of interests among the two sides. This paper analyzes the Russian-EU divide by mainly focusing on the recent Ukrainian crisis and its regional and international impacts and by providing with an in-depth and retrospective analysis of the existing and new Russian and European political and energy projects.
\end{abstract}

Keywords: Russia, European Union, Caspian Region, pipeline politics, energy security, Nabucco, TANAP, TAP, Eurasian Customs Union

* Doç. Dr., Marmara Üniversitesi, Uluslararası İlişkiler Bölümü, emel.parlar@marmara.edu.tr

** Arş. Gör., Marmara Üniversitesi, Uluslararası İlişkiler Bölümü, a.muratkursun@marmara.edu.tr 


\section{Giriş}

3.626.000 kilometre karelik Hazar ve onu çevreleyen ülkeler Azerbaycan, İran, Türkmenistan, Kazakistan ve Rusya, küresel siyasetin önemli çekişme alanlarından birini oluşturmaktadır. Zengin enerji yataklarına sahip olmasının yanı sıra önemli bir geçiş noktası olarak da kabul edilen Hazar bölgesi bir taraftan Rusya diğer taraftan da Avrupa Birliği (AB) tarafından geliştirilen siyasi ve ekonomik projelerle bir çekişme alanı haline gelmiştir. Rusya’nın eski Sovyetler Birliği coğrafyasında yeniden nüfuz alanları yaratmak için geliştirmeye başladığı siyasi projeler ve AB’nin ortaya koymaya çalıştığı demokratik model oluşturma ve enerji transferi projeleri bu çekişmeyi açıkça ortaya koymaktadır.

Bu çekişmenin ortaya çıkmasında ve gelişmesinde Ukrayna’nın önemli bir etkisi bulunmaktadır. 2006 ve 2009 yıllarında yaşanan gelişmelerde görüldüğü gibi gibi Rusya’nın Ukrayna’ya doğal gaz akışını kesmesi ve daha da önemlisi Avrupa’ya giden gazın da kesintiye uğramış olması AB’nin enerji arzı çeşitliliğini ve güvenliğini arttırabilmesi için Hazar bölgesine özel bir ilgi geliştirmesine neden olmuştur. $\mathrm{AB}$ bu ilgisini attığ 1 siyasi adımlar ve geliştirdiği ve desteklediği Nabucco, TANAP ve TAP gibi boru hatları projeleri ile ortaya koymaktadır. Aynı zamanda AB'nin yayınladığı enerji güvenliğine dair belgelerde ortaya konan ilkeler ve stratejiler de gün geçtikçe AB’nin Hazar bölgesinden gelecek olan enerjiye duyduğu ihtiyacı gözler önüne sermektedir. Bunun karşısında Rusya, Güney Akım ve Türk Akımı gibi yeni projeler ile AB projelerine karşı alternatif oluşturmaya çalışmaktadır.

$\mathrm{Bu}$ makale genel olarak Hazar bölgesindeki çatışan Rusya ve AB ekonomi-politik çıkar ve projelerini ve bu çekişmelere "Ukrayna” faktörünün etkisini anlatmaktadır. Bundan hareketle, AB ve Rusya arasında genel olarak Hazar bölgesine yönelik siyasal entegrasyon çekişmesi ve bunun sonucunda Rusya’nın Ukrayna’ya giden gazı keserek enerjiyi bir jeopolitik güç olarak kullanması ve de son olarak da birbiri peşine patlak veren Ukrayna krizlerinin AB’nin son dönemde geliştirdiği ekonomi-politik projelerine olan yansıması tartışılacaktır. Bu çerçevede, ilk olarak Rusya’nın eski Sovyet coğrafyasındaki mevcut etki alanına ve elinde bulundurduğu ekonomipolitik araçlara kısaca değinilecektir. İkinci olarak, Rusya’nın Avrasya Gümrük Birliği projesinin Hazar ülkeleri tarafından nasıl karşılandığı vurgulanarak ve devamında Hazar bölgesine yönelik Avrupa Birliği siyasi entegrasyon projeleri kısaca açıklanacaktır. Dördüncü olarak Avrupa Birliği enerji projelerinin Hazar Bölgesine uzantıları kısaca ele alınacak ve bu çerçevede Bakü Girişimi ve Astana Toplantısı, Ukrayna’ya Gaz Akışını Kesilmesi ve bunun sonucunda AB’nin Enerji Arzı Çeşitliliğini Arttırma Arayışları ve son olarak da AB’nin boru hattı stratejisinin Hazar ayağından bahsedilecektir. Son olarak ise 2013'te tekrar patlak veren ve 2014'te tansiyonun iyice yükseldiği son Ukrayna Krizi Sonrası AB’nin yenilenen enerji stratejisi üzerinde durulacaktır.

\section{Eski Sovyet Coğrafyasında Rus etki alanı ve Hazar}

Sovyetler Birliği’nin çökmesi ve yeni devletlerin ortaya çıkması ile birlikte Rusya, Hazar bölgesi ve çevresindeki tam hakimiyetini kaybetmişti. Bölgesel ve uluslararası güçlerin Hazar ve çevresinde 
daha aktif hale gelmesi de Rusya’nın bu bölgedeki merkezi kontrolünü kaybetmesine sebep olan etkenlerden biriydi. Tüm bunların yanında enerji şirketlerinin bölgede faaliyetlerinin artması da Rus varlığını önemli derecede sarsmıștı (Griffith, 1998, s.427). Ancak Rusya, özellikle 1990’ların ortalarından itibaren bu durumu tersine çevirmeye çalışmış ve eski Sovyet coğrafyası üzerindeki nüfuzunu tekrar tesis etme gayretleri göstermeye başlamıştı. Bu bağlamda, Rusya devlet başkanı Boris Yeltsin’in 14 Eylül 1995’te ilan ettiği “Rusya’nın BDT Ülkelerine Yönelik Stratejik Politikasının Belirlenmesi” kararnamesinde belirtilen eski Sovyet coğrafyasının Rusya’nın dış politikasında tekrar temel öncelik haline getirilmesi ifadesi büyük önem arz etmektedir.

Aynı şekilde Putin'in göreve gelmesinden hemen sonra yayınlanan Ulusal Güvenlik Konsepti (Ocak 2000), Askeri Doktrin (Nisan 2000) ve Dış Politika Konsepti (Haziran 2000) gibi belgeler de Rusya’nın eski Sovyet coğrafyasına olan ilgisinin tekrar tesis edilmesine önem verilmesi gerekliliğini ortaya koymuştur (Kazantsev, 2008, s. 1075). Ancak hem bölge ülkeleri tarafından başlatılan farklı siyasi entegrasyon projelerinin olması, hem de Rusya’nın kendi siyasi entegrasyon projelerinin varlığı ortak ve tek bir siyasi entegrasyon projesi etrafında birleşmeyi engellemektedir. Dolayısıyla Hazar bölgesi ülkeleri genellikle Rusya tarafından başlatılan siyasi projelere ya da kendilerinin başlattıkları farklı projelere ayrı ayrı dahil olmuşlardır. Sadece Türkmenistan kendisini tüm bu projelerden tecrit etmiştir.

\section{Rusya'nın Avrasya Gümrük Birliği Projesi ve Hazar Ülkeleri}

Rusya’nın siyasi entegrasyon projeleri arasında Hazar bölgesi ülkelerinden Kazakistan’n başını çektiği Avrasya Gümrük Birliği projesi öne çıkmaktadır. Avrasya Gümrük Birliği projesinin geçmişi Rusya’nın Ocak 1995’te Belarus ve Kazakistan ile imzaladığg gümrük birliği anlaşmasına dayanmaktadır. Bu anlaşmaya daha sonra Kırgızistan ve Tacikistan da dahil olmuştur. Ancak 2000'de bu topluluk Avrasya Ekonomik Topluluğu adı altında yeniden şekillenmiştir. Avrasya Ekonomik Topluluğu ile birlikte çatışmaların çözümü için özel bir mahkeme de kurulmuştur. Ancak bu mahkemenin fiilen hayata geçmesi Ocak 2012’yi bulmuştur.

Avrasya Ekonomik Topluluğu’nun Haziran 2006'da Minsk'te yaptığ zirvede bir gümrük birliği kurma kararı alınmış ve hızlı bir şekilde Ekim 2007'de bu yeni gümrük birliğinin anlaşması imzalanmıştır. $\mathrm{Bu}$ süreç Temmuz 2011'e kadar devam etmiş ve bu tarihten itibaren sınır kontrollerinin kaldırıldığı açıklanmıştır. Daha önce planlanan mahkemenin kurulmasının yanı sıra Ocak 2012'de Tek Ekonomik Bölge de hayata geçirilmiştir. Aynı zamanda daha önce kurulmuş olan Gümrük Birliği Komisyonu, Avrasya Ekonomik Komisyonu’na çevrilmiştir (Dragneva \& Wolczuk, 2012, s. 2-5). 29 Mayıs 2014'te ise Astana'da Rusya devlet başkanı Vladimir Putin, Kazakistan devlet başkanı Nursultan Nazarbayev ve Belarus devlet başkanı Aleksandr Lukaşenko 1 Ocak 2015’ten itibaren geçerli olacak olan birleşik gümrük tarifesine dair anlaşmayı imzalamışlardır (RFERL, 2014).

Şeklen tamamlanan tüm bu siyasi entegrasyon projesinin pürüzsüz ve sorunsuz biçimde ilerlediğini söylemek mümkün değildir (Süreç ile ilgili ayrıntılı bir çalışma için bkz. Golovnin, 2008, s. 38-53). 
Ülkeler arasındaki bir takım karşılıklı problemler birliğin ilerlemesinde ve genişlemesinde bir engel olarak görülebilir. Yukarıda da belirtildiği gibi Türkmenistan’ın her türlü siyasi entegrasyon projesinden kendisini tecrit etmiş olması doğal olarak tüm Hazar bölgesi ülkelerinin ileride bu projeye dahil olabileceği yönündeki beklentileri boşa çıkarmaktadır. Rusya’nın Ermenistan’ı birliğe katma teklifini Kazakistan’ın başta reddetmesine rağmen Ermenistan’ın da bu birliğe üye olması bir diğer Hazar bölgesi ülkesi olan Azerbaycan’ı bu birliğin dışarısında bırakacaktır. Ermenistan, Belarus, Kazakistan, Kırgızistan ve Rusyadan oluşan bu birliğin yine bir Hazar ülkesi olan İran ile serbest ticaret yapabileceğine dair bir fikir birliğine de varılmıștır. Ermenistan’ın başkenti Erivan'da Mayıs 2015’te yapılan bir toplantıda İran ile serbest ticaret anlaşması yapma fikri tüm üyeler tarafından onaylanmıştır (Press TV, 2015).

Görüldüğü üzere, bu projede iki Hazar bölgesi ülkesi (Rusya ve Kazakistan) kurucu üye olarak yer almıştır. Bir diğer Hazar bölgesi ülkesi olan İran ile serbest ticaret anlaşması yapılmasının onaylanması ileriye dönük işbirliği açısından önemli olduğu değerlendirilmektedir. Ancak Azerbaycan için bu birlik ile ileriye dönük güçlü bir işbirliğinden söz etmek Ermenistan’ın bu birliğe üye olmasından dolayı pek mümkün gözükmemektedir. Ayrıca Türkmenistan’ın da izlediği politikalar bu birliğe üye olmasını engelleyecektir. Dolayısıyla Avrasya Gümrük Birliği projesinin Hazar bölgesi ülkelerini tam olarak entegre etmiş bir siyasi proje olduğu iddia edilemese de projenin bu ülkeleri nispeten siyasi açıdan birbirine yaklaştırmış olduğu ileri sürülebilir.

\section{Avrupa Birliği Siyasi Projelerinin Hazar bölgesine etkileri: Avrupa Komşuluk politikası ve Doğu Ortaklığı}

Avrupa Birliği de aynı şekilde Rusya gibi doğu ve güney komşularına yönelik siyasi entegrasyon projeleri başlatmış ve projeler ile demokratik fikir ve kurumların bu bölgelere yayılması yönünde atılımlar gerçekleştirmiştir. İlk olarak, Avrupa Birliği’nin 2004 yılında başlattığı Avrupa Komşuluk Politikasından bahsetmek gerekir ki bu politika çerçevesinde yer alan ülkeler arasında Azerbaycan, Belarus, Cezayir, Fas, Filistin, Ermenistan, Gürcistan, İsrail, Lübnan, Libya, Mısır, Moldova, Suriye, Tunus, Ukrayna, Ürdün bulunmaktadır. AB’nin en önemli dış politika projelerinden biri olan Avrupa Komşuluk Politikası ile $\mathrm{AB}$ bu ülkelerde demokratik yönetim, hukukun üstünlüğü ve insan hakları gibi değerlerin tesis edilmesini hedeflemekteydi. Bu bağlamda, AB bu proje ile bu ülkelere maddi yardım yapmak, ekonomik entegrasyonu sağlamak, AB ülkelerine daha kolay seyahat etme imkanı, teknik ve siyasi destek vermek gibi amaçlara sahipti. Şu an için Cezayir, Belarus, Libya ve Suriye dışındaki 12 ülke Avrupa Komşuluk Politikası’na tam olarak ortaklık etmektedir. AB’nin verdiği rakamlara göre bu proje çerçevesinde 2011'de AB Avrupa Komşuluk Politikası ortakları ile 230 milyar euro değerinde ticaret gerçekleştirilmiş ve 2012'de AB bu ortaklara 3.2 milyon adet Şengen vizesi vermiştir (ENP websitesi).

AB, Komşuluk Politikası çerçevesinde 2009 yılında İsveç'in ve Polonya’nın önerisiyle Azerbaycan, Belarus, Ermenistan, Gürcistan, Moldova ve Ukrayna’yı kapsayan AB Doğu Ortaklığı projesini başlatmıştır (Mayıs 2009'da yayınlanan Prag Zirvesi Ortak Bildirisi için bkz. (Council of the 
European Union, 2009). Bu proje de yine AB’nin Komşuluk Politikası projesi bağlamında hedeflediği bölgesel istikrarın sağlanması ve demokratik fikir ve kurumların tesis edilmesi amaçlarını taşımaktadır. $\mathrm{Bu}$ proje kapsamında $\mathrm{AB}$ bu ülkeler ile birçok inisiyatifi hayata geçirmiştir. Örnek olarak, Bütünleşmiş Sınır Kontrolü Programı (IBM) (44.5 milyon euro bütçeli), Küçük ve Orta Ölçekli Yatırım Serbestisi (SME) (57 milyon euro bütçeli), Bölgesel Elektrik Pazarı, Yenilenebilir Enerji Kaynakları ve Enerji Etkinliği (41 milyon euro bütçeli), Çevre Yönetişimi (12 milyon euro bütçeli), Doğal ve İnsan Kaynaklı Afetlerin Önlenmesi, Hazır Olma ve Müdahale (12 milyon euro bütçeli) projeleri verilebilir (Eastbook EU, 2015).

Burada altının çizilmesi gereken nokta, AB’nin hayata geçirdiği tüm bu doğu ve güney komşulara yönelik projelerin Rusya tarafından eleştirilere uğramış olmasıdır. Örneğin Rusya Dış İşleri Bakanı Sergey Viktorovich Lavrov Mart 2009'da AB Doğu Ortaklığı Programını, AB’nin kendi etki alanını genişletmeyi amaçlayan bir proje olarak değerlendirmiştir (Pop, 2009). Her ne kadar Rusya bu projeleri kendi sınırları etrafında AB’nin etki alanını genişletmek olarak görse de AB’nin bu projeleri aynı şekilde etkisizliği ve yetersizliği açısından da eleştirilmiştir. Bu bağlamda en önemli eleştiri bu projelerin hiç birisinin bir AB perspektifi sunmadığı, yani AB’ye tam üyelik vaadi vermediğine yöneliktir (Park, 2014). Aynı şekilde bu projelerin tüm üyeleri kapsaması gerektiğine, hızlı etki oluşturabilmek için eylem kapasitesini artırmasının gerekliliğine ve demokratik değerleri teşvik etmek için daha gelişmiş yaklaşımlara ihtiyaç duyulduğuna dair sert eleştiriler de bulunmaktadır (Lehne, 2014).

Hazar bölgesi ülkeleri açısından bakıldığında AB’nin siyasi projeleri yetersizdir. AB Komşuluk Politikası ve AB Doğu Ortaklığı projelerinde Azerbaycan hariç herhangi bir Hazar bölgesi ülkesi bulunmamaktadır. Ancak bu durum AB’nin Hazar bölgesi ülkelerine dair projeler geliştirmediği anlamına gelmemektedir. Bilakis AB Hazar bölgelerine yönelik siyasi projelerden daha çok enerji transferine yönelik projeler gerçekleştirmiştir.

\section{Avrupa Birliği Enerji Projelerinde Hazar'ın yeri ve yeni arayışlar}

AB, Hazar bölgesi ülkelerine özellikle enerji konusunda ihtiyaç duymaktadır. Örneğin Azerbaycan, AB’nin enerji ithal ettiği Doğu Ortaklığı üyeleri arasında \%84lük bir oran ile en büyük paya sahip olan ülke konumundadır (Eurostat, 2015). AB enerji açısından Hazar bölgesi ülkelerine duyduğu ihtiyacı Bakü Girişimi (2004), ve onu takip eden Astana Toplantısı (2006) ve birçok boru hattı projesi ile ortaya koymuştur.

\section{a. Bakü Girişimi ve Astana Toplantısı}

AB, Komşuluk Projesi çerçevesinde Hazar’a ve Karadeniz’e kıyısı olan ülkeler ile enerji taşımacılığı ve "enerji piyasalarının aşamalı olarak AB piyasasıyla bütünleşmesi” (Dağdemir, 2007, s. 261) amacıyla Bakü Girişimi’ni başlatmıştır. Bakü Girişimi, TACIS (Bağımsız Devletler Topluluğu’na Teknik Yardım) tarafından fonlanmış bir INOGATE programıydı (Raszewski, 2010, s. 144). Bakü 
Girişimi, 13 Kasım 2004'te Bakü’de Avrupa Komisyonu ve Azerbaycan, Bulgaristan, Ermenistan, Gürcistan, İran (gözlemci), Kazakistan, Kırgızistan, Özbekistan, Rusya (gözlemci), Romanya, Tacikistan ve Ukrayna’nın katıldığı Enerji Bakanları Konferansı’nda başlatılmıştır. Girişimde Hazar petrolü ve doğalgazının AB’nin enerji güvenliği açısından önemli olduğu ve bu enerji kaynaklarının Rusya, İran ya da Türkiye üzerinden Avrupa’ya taşınmasının önemi vurgulanmıştır (European Comission Directorate, 2015).

Bakü Girişimi başladıktan 2 yıl sonra 30 Kasım 2006'da Kazakistan’ın başkenti Astana'da yapılan zirvede AB ile Karadeniz’e ve Hazar Denizi’ne kıyı ülkeler ve komşuları gelişmiş enerji işbirliğine dair bakanlar düzeyinde bir bildiri yayınlamıștır. Buna göre Bakü Girişimi’ne katılan ülkeler Avrupa Komisyonu tarafından hazırlanan Yol Haritası’nı kabul etmişlerdir. Bakü Girişimi ile 2004'te kurulan dört çalışma grubunun düzenli olarak toplantılara devam etmesi de ayrıca bu bildiride yer almıştır. Ayrıca Avrupa Komisyonu’nun Yol Haritası’nın uygulanmasında gözlemci rolü de desteklenmiştir (Ministerial Declaration, 2006, s. 1-3). Düzenlenen Yol Haritası’nda ise şu dört alanda iş birliği hedeflenmiştir: Enerji Pazarlarının Bütünleştirilmesi, Enerji Güvenliğinin Geliştirilmesi, Sürdürülebilir Enerji Gelişiminin Desteklenmesi, Ortak Çıkar Doğrultusunda Enerji Projeleri Yatırım Çekiciliği (Ministerial Declaration, 2006, s. 5-11).

$\mathrm{Bu}$ iki girişime hedefleri ve içeriği açısından bakıldığında AB’nin Hazar Denizi ve Karadeniz’e kıyısı olan ülkelerle enerji merkezli stratejik işbirliğini kurumsal düzeye taşıma arzusunda ısrarcı olduğunu söylemek yanlış olmaz. Bu iki girişim AB’nin bundan sonraki dönemde de güvenli enerji taşımacılığı başta olmak üzere bölge ülkeleriyle enerji merkezli ticari ortaklığını garantiye almak ve daha da arttırmak içim çaba göstereceğinin bir kanıtıdır.

\section{b. Ukrayna'ya Gaz Akışının Kesilmesi ve AB'nin Enerji Arzı Çeşitliliğini Arttırma Arayışları}

Rusya ve AB’nin Hazar bölgesi ülkelerine yönelik bu proje çekişmelerini, AB açısından daha da önemli hale getiren ve her ikisinin siyasi projelerini fiziki transit projelere çevirmesine ve bu yönde ciddi adımlar atmasına sebep olan en önemli faktörlerden biri yukarda da vurgulandığ üzere $A B$ ’nin enerji güvenliğini sağlama çabasıdır. $A B$, günümüz itibariyle önemli ölçüde Rus doğal gazına bağımlıdır. Bu durumu rakamlar ile ifade etmeye çalışırsak, AB Komisyonu'nun da belirttiği şöyle bir tablo ile karşılaşmaktayız: Altı AB üyesi ülkenin (Bulgaristan, Estonya, Finlandiya, Letonya, Litvanya ve Slovakya) gaz ithal ettiği tek ülke Rusya'ır ve bunun yanında 2013'te Rus gazı toplam AB gaz ithalinin \%39'unu oluşturmuştur ki bu oran AB gaz tüketiminin de \%27'isine denkti (Dickel \& Hassanzadeh \& Henderson \& Honore \& El-Katiri \& Pirani \& Rogers \& Stern \& Yafimava, 2014, s. 6). Rusya’nın da gaz ihracatının \%61.7’sinin AB'ye gittiğini göz önünde bulundurursak esasında bunun tek taraflı bir bağımlılık olduğunu söylemek güçtür. Ancak Rusya bu durumu özellikle Mayıs 2014’te Çin ile imzaladığ 1 anlaşma ile değiştirmeye çalışmakta ve ihracat yollarını çeşitlendirmeye gitmektedir (de Micco, 2014, s. 5).

Dolayısıyla Rusya açısından, AB ülkelerine gaz ihracatı sadece ekonomik bir gelir değil, aynı zamanda jeopolitik bir araç konumundadır. Bu aracın farkında olan Rusya, bunu kullanmaktan 
da çekinmemiştir. Bunun en büyük göstergelerinden biri Rusya’nın 2006, 2009 ve son olarak 2014'te Ukrayna'ya olan gaz ithalatını durdurması ve bunun sonucunda ise AB ülkelerine Ukrayna üzerinden giden gazın da önemli ölçüde etkilenmesidir. . Ukrayna’nın AB ülkeleri açısından Rusya'dan gelen gazın AB’ye transfer edilmesi noktasında önemli bir pozisyona sahip olduğu ortadadır. 1991-2000 yılları arasında Avrupa'ya giden Rus gazının \%90'dan fazlası Ukrayna vasıtasıyla transfer edilmiştir (Chyong, 2014, s. 2). Rusyảnın şu anda söz konusu transit yollarını çeşitlendirme girişimlerini hayata geçirmesi sonucu (Belarus, Kuzey Akım, Mavi Akım vs.) bu oranın oldukça azaldığı söylenebilir. Böyle olmakla birlikte AB ülkelerine giden gazın hala yaklaşık \%15’i Ukrayna üzerinden gelmektedir ki bu da (Ramesh, 2014) Ukrayna’ya giden gazın Rusya tarafından kesilmesinin $\mathrm{AB}$ enerji gereksinimi açısından nasıl büyük bir sorun olduğunu göstermesi açısından önemlidir.

Ocak 2006'da Ukrayna'ya giden Rus gazının ilk defa kesilmesi ile AB’ye Ukrayna üzerinden giden gaz da kesintiye uğramıștır. Turuncu devrimlerin Ukrayna'da değiştirdiği hükümetin göreve gelmesinden yaklaşık bir yıl sonra Rusya ile Ukrayna arasında fiyatlandırma sebebiyle bu sorun ortaya çıkmıştır. Tabi ki burada sadece ekonomik bir çatışmadan bahsetmek mümkün değildir. Rusya’nın gaz kesintisini Ukrayna’da başa gelen batı yanlısı Viktor Yuşçenko’nun ülkedeki meşruiyetini zayıflatmak için kullandığı da ileri sürülebilir. Ancak burada Rusya’nın Ukrayna’ya gaz satma yönteminde bir değişikliğe gitmeye çalıştı̆̆ını söylemek de yerinde olacaktır. Bu noktada hatırlatmak gerekir ki Ukrayna krizi ortaya çıkmadan önce Rusya Ukrayna'ya gazı daha düşük bir fiyat üzerinden satmakta ve Ukrayna'da ucuz Rus gazının Avrupa'ya güvenli ve uygun bir fiyat üzerinden transferini sağlamaktaydı (Chyong, 2014, s. 2). Son Ukrayna krizinde Rusya’nın bu sistemi değiştirerek gaz satış fiyatlarını önemli ölçüde artırmak istediğini (Rusya 1000 metreküp gazın fiyatını 50 dolardan 220-230 dolara çıkarmayı hedeflemiştir. Bkz. Kramer, 2006) ve stratejik olarak da bu durumu gelişen AB-Ukrayna ilişkilerinin önüne set koymak için yaptığı ileri sürülebilir.. Ukrayna Rusya’nın kendilerine önerdiği yeni fiyatı reddetmiş ve bunun neticesinde dereceli olarak fiyat artışı önermiştir. Bunun üzerine Rusya Ukraynàya ödemeyi yapmak için kredi verme ya da fiyatı üç aylığına dondurma teklifleri yapmış, ancak Ukrayna bu teklifleri reddetmiştir. Fiyatta anlaşılamaması üzerine Rusya, 1 Ocak 2006'da Ukrayna’ya olan gaz akışını 3 gün kesmiştir. Bunun üzerine örneğin Macaristan’a Ukrayna üzerinden giden gazda \%25 oranında azalma olmuş (Parfitt, 2006) ve çözüme ancak 4 Ocak 2006'da varılabilmiştir. Varılan anlaşmaya göre Ukrayna gazı yine yarısına Gasprom'un sahip olduğu Rosukrenergo şirketi üzerinden alacaktı. Rosukrenergo gazı Rusya'nın istediği fiyat olan 230 dolara Rusya'dan ve ayrıca daha ucuza Türkmenistan'dan alacak ve Ukrayna'ya 95 dolar civarında satacaktı (BBC, 2006). Her ne kadar sonunda bir anlaşmaya varılmış olsa da bu krizin 2009'da yeniden patladığına şahit oluyoruz (2009 krizi ile ilgili ayrıntılı bir çalışma için bkz. Pirani \& Stern \& Yafimava, 2009).

2009 yılında yaşanan kesinti yine fiyat konusundaki anlaşmazlıktan kaynaklanmaktaydı. Fiyatlara zam yapmak isteyen Rusya’nın Gazprom şirketi 1000 metreküp gaz için Ukrayna’dan 250 dolar istedi. Ukrayna’nın fiyata itiraz etmesi ve 210 dolar civarında bir fiyatı kabul edeceğini söylemesi üzerine Gazprom Avrupa ülkelerinin 1000 metreküp gaz için 500 dolar civarında ödediğini belirtip, Ukrayna’nın şansını kaybettiğini söyleyerek fiyatı 418 dolara yükseltti. Ayrıca 
Ukraynảnın 2008 yllından kalma 600 milyon dolarlık borcunun da olduğunu hatırlattı. Yine fiyatta anlaşılamaması üzerine Rusya 01 Ocak 2009'da Ukrayna’ya tekrar gaz akışını kesmiş ve bunun doğal sonucu olarak bu gaz kesintisinden $\mathrm{AB}$ ülkeleri de doğrudan etkilenmiştir (Kramer, 2009). Daha sonrasında ise iki ülke arasında 10 yıllığına yapılan anlaşmaya göre göre Rusya Ukrayna'ya \%20'lik bir indirim sağlamayı kabul etmiş ve bunun karşıllı̆̆ında Ukrayna AB'ye gaz gönderme fiyatını 2009'da da 2008'deki fiyat üzerinden devam etme kararı almıştır (Shi, 2009, s. 56). Bu iki benzer krizin devamını ise Kırım’n Rusya tarafından ilhakıyla sonuçlanacak olan son 2014 Ukrayna krizinde daha şiddetli bir şekilde görüyoruz.

Rusya, Ukrayna’ya gaz satı̧s fiyatına 2042'ye kadar Kırım’da Rus donanmasının kalması karşıllı̆ında 2010'da \%30 indirim yapmıştı. Aynı şekilde iddiaya göre, 2013’te Rusya, Ukrayna’ya sağladığı \%33'lük indirimi $\mathrm{AB}$ Ortaklık Anlaşması̉nın imzalanmaması koşuluyla yapmıştı. Ancak Yanukoviç iktidarını kaybettikten sonra Rusya bu indirimleri iptal etmiştir. Ukrayna hükümeti de iptal edilmiş fiyatları ödemeyi reddetmişti ki, zaten geçmişe mahsuben de yaklaşı 5.3 milyar dolar borcu bulunmaktaydı. Yapılan görüşmelerin sonuç vermemesi üzerine 16 Haziran 2014'te Rusya Ukrayna'ya gaz akışını yeniden kesmiştir ve Kırım’ı işgal etmiştir (Chyong, 2014, s. 5). Bu krizin şu an için geldiği nokta ise AB’nnin garantörlüğünde Ukraynảnın Rusyaya olan borçlarının aşamalı olarak ödeyeceği taahhütü ve 2015'in ilk çeyreği için de gaz fiyatının 365 dolara yükseltilmesidir (Kirby, 2014).

Yaşanan tüm bu krizler ve gaz transferinde Ukrayna’ya bağımlı olması sebebiyle $\mathrm{AB}$ gazının kesilmesi, $A B$ 'yi enerji arz güvenliğini çeşitlendirme ve Rus gazına olan bağlllığını düşürme arayışlarına yöneltmiştir. Bu bağlamda AB’nin özellikle Hazar bölgesi ülkelerinden enerji akışını Avrupa'ya güvenli bir şekilde getirme projeleri gündeme gelmiş ve bu yönde adımlar atılmıştır. Dolayısıyla Rusyảnın Ukrayna ile yaşadığı krizler AB’yi Hazar bölgesi ülkelerine yönelik projelerini daha da yoğunlaştırmaya, stratejik işbirliğini geliştirmeye ve mevcut ortaklığg fiziki projelere dönüştürmeye zorlamıştır.

\section{c. AB'nin Hazar Stratejisinin Boru Hattı Ayağı}

Enerji güvenliğinin tehlikeye girmesi, $A B$ 'yi enerji güvenliğini ve enerji arzı çeşitliliğini arttırma arayışlarına yönelterek, başlattığı diğer siyasi atılımlar çerçevesinde Ortadoğu ülkelerine ve Hazar bölgesi ülkelerine yönelik geliştirdiği projelere enerji boyutunu da eklemeyi ihmal etmemiştir. Enerji güvenliğini ve enerji arzı çeşitliliğini artırma ve özellikle Hazar bölgesi ülkelerinden gelecek enerjiyi Avrupa ülkelerine güvenli bir şekilde taşıma noktasında AB’nin ortaya koyduğu önemli bir belgeyi ve bir deklarasyonu incelemekte fayda vardır. Zira bu belge ve deklarasyon ile birlikte $\mathrm{AB}$ kendi açısından önemli enerji taşıma projelerini destekleme kararı almış ve bu yönde atılımlar yapmıştır.

AB’nin enerji güvenliğini ve enerji arzı çeşitliliğini arttırma yönünde ortaya koyduğu en önemli belgelerden biri 13.11.2014 tarihinde Avrupa Komisyonu tarafından yayınlanan "İkinci Stratejik Enerji İncelemesi: AB Enerji Güvenliği ve Dayanışma Eylem Planı” (Second Strategic 
Energy Review: A EU Security and Solidarity Action Plan) başlıklı belgedir. AB'nin 2007'de yayınladığı birinci belgedeki odak noktası daha çok iklim değişikliği çerçevesinde şekillenmiş iken bu belgede yaşanan krizler de dikkate alınarak enerji arzı güvenliği ve çeşitliliği üzerinde durulmuştur.

Belge girişinde, genel olarak AB’nin enerji durumundan bahsederken 2020'de enerji tüketiminin alınacak tedbirler ile \%15 dolaylarında azalacağını ve enerji ithalatının da yine \%26 oranında düşeceğini, ancak yine de AB’nin enerji kaynaklarını ve arzını çeşitlendirmeye ihtiyaç duyduğu vurgulanmaktadır (Second Strategic Energy Review, 2008, s. 2). Belgenin ortaya koyduğu beş adet odak noktası ise şunlardan oluşmuştur:

- Altyapı ihtiyaçları ve enerji arzının çeşitlenmesi,

- Dış enerji ilişkileri,

- Petrol ve doğalgaz stokları ve krize müdahale mekanizmaları,

- Enerji etkililiği,

- AB'nin kendi enerji kaynaklarının en iyi şekilde kullanımı (Second Strategic Energy Review, 2008, s. 3).

Belgenin ortaya koyduğu bu beş odak noktasından da anlaşıldığı üzere AB bu belge ile birlikte enerji stratejilerinde enerji çeşitliliğini ve güvenliğini ana hedefi haline getirmiştir.

Belgede bu hedefi gerçekleştirmek için verilen altyapı önceliklerinden bir tanesi Güney Gaz Koridorudur. Hazar bölgesi ve Ortadoğu kaynaklarından enerji sağlayacak olan bu koridordan AB’nin en önemli enerji güvenliği önceliklerinden biri olarak bahsedilmiştir. Hazar bölgesi ülkelerinden Azerbaycan ve Türkmenistan belgede birlikte çalışılması gereken ülkeler olarak anılmış ve yine bir diğer Hazar bölgesine kıyısı olan İran, siyasal koşullar el verdiği takdirde enerji arzı sağlanabilecek ülkelerden biri olarak sayılmıştır (Second Strategic Energy Review, 2008, s. 4). Dolayısıyla $A B$ bu belge ile birlikte Hazar bölgesi ülkelerine olan ihtiyacını bir kere daha vurgulamış ve daha da ötesi bu ihtiyacı stratejik bir hedef olarak da ortaya koymuştur. Ayrıca bu bölgelerden gelecek olan enerjinin güvenliğine ve yollarının çeşitlenmesine olan ihtiyacını da vurgulayarak bu yöndeki projelere desteğini belirtmiştir. Dolayısıyla bu belge önemli bir nitelik arz etmektedir.

Bu bağlamda Prag'da yapılan Güney Koridoru zirvesinin ardından 8 Mayıs 2009 tarihinde AB bir deklarasyon yayınlamıştır. Avrupa Konseyi ve Komisyonu yetkililerinin yanı sıra Azerbaycan, Gürcistan, Türkiye, Mısır, devlet başkanlarının ve Kazakistan, Türkmenistan ve Özbekistan temsilcilerinin katıldı̆̆ı zirve sonucunda imzalanan deklarasyonda Güney Koridoru’nun gerçekleştirilmesi için gereken siyasi desteğin verildiği belirtilmiştir. Deklarasyon ayrıca Güney Koridor kavramının hukuki ve siyasi alt yapısını oluşturan belgelerin listesini de vermiştir. Aynı zamanda deklarasyonda Güney Koridor kavramının ülkeleri ve insanları bağlayan yeni bir İpek Yolu olarak dikkate alındığı da ortaya konulmuştur (Declaration: Prague Summit, 2009). 
“İkinci Stratejik Enerji İncelemesi: AB Enerji Güvenliği ve Dayanışma Eylem Planı" ve "Prag Zirvesi Güney Koridoru Deklarasyonu” gibi iki önemli belgenin AB’nin enerji çeşitliliğini ve arz güvenliğini çeşitlendirme yolunda özellikle Hazar bölgesi ülkeleri ile yapılan ve yapılacak olan projelerin alt yapısını ve gerekli işbirliğini hazırladığını söyleyebiliriz. Bu belgelerde ortaya konan gereksinimler, hedefler, işbirliği niyeti çerçevesinde, Hazar bölgesi ülkelerinden gelecek olan enerjinin $\mathrm{AB}$ ülkelerine taşınmasına yönelik bir takım boru hatları projeleri de ortaya konmuștur. $\mathrm{Bu}$ projeler arasinda Nabucco, TANAP (Trans-Anadolu Boru Hattı) ve TAP (Trans-Adriyatik Hattı) sayılabilir.

AB’nin Rusya’ya ve bir transit yolu olarak Ukrayna’ya olan bağımlılı̆ıını azaltmak amacıyla desteklediği projelerin en önemlilerinden biri Nabucco projesidir. Projenin ortaya çıkışı 2002 yllına kadar geri gitmektedir. 2002'de Avusturya ve Türkiye tarafından ortaklaşa Nabucco fikri ortaya atılmış ve AB'den bu fikrin araştırılması ve gerekli alt yapının hazırlanması için teknik çalışmaların yapılması amacıyla fon alınmıştır. Gerekli teknik araştırmalar yapıldıktan sonra Nabucco projesinin hayata geçirilmeye uygun olduğu anlaşıldığında bu projeye $\mathrm{AB}$ tam destek vermiş ve 2008'de yayınladığı belgede bunu açıkça ortaya koymuştur.

Nabucco projesine göre Hazar bölgesi ülkelerinden, Orta Asya'dan ve Ortadoğu’dan gelecek olan enerji Türkiye üzerinden Bulgaristan, Romanya, Macaristan’ı dolaşarak Avusturya’ya ulaşacaktı. Proje kapsamında 3300 kilometrelik bir boru hattının döşenmesi planlanmaktaydı. Bu boru hattıyla taşınacak olan gaz ise yıllık yaklaşık 31 milyar metreküp civarında olacaktı. Planlara göre 2011 yılında başlatılacak olan Nabucco’nun 2019 yılında tam kapasite ile çalışmaya uygun hale gelmesi beklenmekteydi. Temmuz 2009'da ilgili ülkeler (Türkiye, Avusturya, Bulgaristan, Macaristan ve Romanya) bir araya gelerek projenin hukuki çerçevesini oluşturacak anlaşmayı imzalamışlardı (The Quaker Council for European Affairs, 2009, s. 6-7). 2010 yılında projenin yatırım maliyetinin 8 milyar euro civarında olduğu belirtiliyordu (Uluatam, 2010, s. 67). Ancak Nabucco konsorsiyumu projenin maliyetlerinden dolayı Nabucco projesinin tamamının yapılamayacağını belirterek yaklaşık yarı kapasitedeki Nabucco Batı projesine devam edileceğini ilan etti. Aynı şekilde Şah Deniz konsorsiyumu da TAP (Trans-Adriyatik Hattı) ve Nabucco Batı projesi ile devam edileceğini açıklamıştı (Kusznir, 2013, s. 2). Ancak şu anda gaz Avrupa’ya TAP ile taşınacaktır.

TAP ile Avrupa'ya taşınacak olan gaz TANAP (Trans-Anadolu Boru Hattı) ile Türkiyeyi geçecektir. Azerbaycan’ın SOCAR ve Türkiye’nin BOTAŞ şirketlerinin yaptıkları anlaşma sonucunda ortaya atılan bu boru hattı fikri ile yaklaşık 16 milyar metreküp gaz taşınması planlanmıştır. 6 milyar metreküpü Türkiyede kalacak olan gazın 10 milyar metreküpü ise Avrupaya taşınacaktır (Kusznir, 2013, s. 2). TANAP’ın taşıyacağı gazın kaynağı olarak da Azerbaycan’nn Şah Deniz II sahasında bulunan altı yeni kaynak gösterilmektedir (Güney, 2014, s. 29). 2011'de ortaya çıkan TANAP fikrinin temeli ise Bakü'de 20 Eylül 2014 tarihinde atıldı. TANAP’ın taşıyacağı gaz miktarının 2026'da yıllık 31 milyar metreküpe çıkması beklendiği belirtilmişti. TANAP’a Azeri gazının yanında diğer Hazar bölgesi ülkelerinden Türkmenistan ve İran gazının eklenmesi de tartışılan konular arasında bulunmaktadır (İșeri, 2014). Her ne kadar Nabucco ile başarısızlığa uğramış 
olsa da TANAP ile birlikte AB'nin planladığ 1 Güney Gaz Koridorunun da fiziki olarak temelleri atılmış oldu. Bu sayede doğrudan Hazar bölgesinden Avrupa'ya giden gaz Rusyảnın kontrolü altında olmayacaktır (Cain, 2012, s. 19).

TANAP’tan gelen gazın Avrupa'ya taşınması ise TAP (Trans-Adriyatik Hattı) ile sağlanacaktır. Buna göre TANAP ile Azerbaycan'dan Türkiye vasıtasıyla Yunanistan sınırına kadar gelen gaz, TAP ile Yunanistan'dan Arnavutluk’a ve Adriyatik denizi aracılığıyla İtalya'ya gidecek ve oradan da Avrupa’ya yayılacaktır. Norveç, İsviçre ve Almanya şirketlerinin ortaklığıyla başlatılan bu proje ile 10 milyar metreküp gazın Avrupa'ya transferi hedeflenmektedir. Şubat 2013'te Arnavutluk, İtalya ve Yunanistan hükümetleri TAP için gerekli olan hükümetler arası anlaşmayı imzalamıştır. Haziran 2013'te Şah Deniz konsorsiyumunun güzergah olarak TAP'ı tercih etmesi projeye hız kazandırmıştır. 2015 planlamasına göre Arnavutluk’ta başlayacak olan çalışmalar ile birlikte 2016 yılında boru hatlarının döşenmesine başlanacaktı. Planlamaya göre ise 2018 yılında Şah Deniz'in Gürcistan’a ve Türkiye’ye gaz akışını başlatmasından yaklaşık bir yıl sonra TAP da Avrupa'ya gaz transferine başlayacaktı (TAP resmi sitesi).

AB’nin tüm Nabucco ile başaramadığı süreç TANAP ve TAP ile hayata geçirilecek gibi gözükmektedir. Bunun karşısında tabi ki Rusya’nın yeni meydan okumalarının su yüzüne çıktığını görüyoruz. Rusya’nın başlattığı Güney Akım projesi ve sonrasında bu projeyi iptal etmesi ve de ardından, Türk Akımı adlı yeni bir projeyi destekleyeceğini duyurması da bu meydan okumalara örnek teşkil etmektedir (Türk Akımı hakkında bilgi için bkz. Karagöl \& Kızılkaya, 2015). Her halükarda Güney Gaz Koridoru ile birlikte Hazar gazının AB ülkelerine gidecek olması AB’nin ortaya koyduğu enerji güvenliği hedefleri açısından son derece önemlidir.

\section{2013 Ukrayna Krizi Sonrası AB'nin yenilenen Enerji Stratejisi}

AB’nin bu projeleri başlatmada Rusyảnın Ukrayna’ya ve oradan Avrupa'ya giden gaz akışını kesmesinin önemli bir rolü olduğu gibi, Kasım 2013’te başlayan ve sonrasında Mart 2014'te Kırım’nn Rusya tarafından işgal ve ilhak edilmesiyle devam eden yeni Ukrayna krizi AB’yi de enerji güvenliği konusunda yeni arayışlara ya da yeni anlayışlara yöneltmiştir. Bu bağlamda Avrupa Komisyonu’nun 28 Mayıs 2014 tarihinde yayınladığı “Avrupa Enerji Güvenliği Stratejisi” (European Energy Security Strategy) büyük önem arz etmektedir.

Belgenin girişinde 2006 ve 2009 kışlarında yaşanan Ukrayna krizlerine atıf yapılmış ve bu krizlerin ortak bir Avrupa enerji siyaseti ihtiyacına yönelik bir uyanış çağrısı olduğu vurgulanmıştır (European Energy Security Strategy, 2014, s. 2). Belgede AB’nin alt yapısını güçlendirmeye ve enerji arzını çeşitlendirmeye yönelik her türlü girişimi yapmış olmasına rağmen, enerji krizlerinde hala zarar görebilecek konumda olduğu ortaya konmuştur. Daha da önemlisi bu belge ile birlikte enerji güvenliğine yönelik kısa, orta ve uzun vadede atılması gereken sekiz adet ana strateji ortaya konmuştur. Bu stratejiler sırasıyla şunlardır (European Energy Security Strategy, 2014, s. 3): 
- 2014/2015 kışında olabilecek büyük bir kesintiye karşı AB’nin kapasitesini arttırmaya yönelik acil eylemler,

- Risk değerlendirmelerinin koordinasyonu, beklenmedik durum planları ve stratejik altyapının korunması dahil olmak üzere acil/dayanışma mekanizmalarını güçlendirmek,

- Enerji talebini azaltmak,

- İyi işleyen ve tamamen entegre olmuş bir iç pazar inşa etmek,

- $\mathrm{AB}$ içerisinde enerji üretimini arttırmak,

- Enerji teknolojilerini daha da geliştirmek,

- Dış arzı ve ilgili altyapıyı çeşitlendirmek,

- Ulusal enerji politikalarının koordinasyonunu geliştirmek ve diş enerji politikasında birlik sağlamak.

Yukarıda verilen bu sekiz adet strateji AB’nin enerji arzı çeşitliliğini ve güvenliğini arttırmaya olan bağlılı̆̆ını ve hedeflerini ortaya koymaktadır. $\mathrm{AB}$ artık bu belge ile stratejilerini daha pragmatik bir seviyeye çektiğini göstermiştir. $\mathrm{AB}$ içi düzenlemeler haricindeki tüm maddeler esasında doğrudan Hazar bölgesinden gelecek gaz ve onu taşıyacak boru hatları ile doğrudan ilgilidir.

$\mathrm{Bu}$ açıdan bakıldığında yukarıdaki stratejiler doğrultusunda AB’nin Hazar bölgesi ülkelerinden gelecek gazı taşıyacak olan boru hatlarının kapasitesini arttırmaya yönelik adımlar atacağı ve teşvikler verileceği öngörülebilir. Kırım’ın işgalinden sonra AB’nin Rusya ile olan Güney Akım ve Kuzey Akım hatları ile ilgili görüşmelerini durdurması da bu yönde atılabilecek adımlara işaret etmektedir. AB’nin hem Hazar'dan gelecek gazı taşıyacak olan hatların geliştirilmesi için bu ülkeler ile daha fazla ticari ilişkilere girebileceği de yapılan öngörüler arasında bulunmaktadır (Hafner, 2014, s. 32). Aynı şekilde ABD’nin İran ile yaptığı nükleer anlaşmalar sonrasında AB’nin de İran ile ticari ilişkileri başlatması halinde İran gazının da bu projelere eklemlendirilmesi AB’nin bu stratejileri açısından büyük bir fayda sağlayabilecektir. Ancak Tahran ve Moskova arasındaki işbirliği göz önüne alındığında bunun ne derece yapılabilir olduğu da kuşkusuz büyük bir sorun teşkil etmektedir.

\section{Sonuç}

İki kutuplu düzenin sona ermesiyle birlikte Rus tekelinden kurtulan Orta Asya ve Hazar ülkelerine yönelik bir çok proje hayata geçirilmeye çalışılmıştı. Rusya’nın özellikle Putin ile birlikte eski Sovyet coğrafyasına artan ilgisi bir taraftan hayata geçirilmesi planlanan yeni projelerin önüne set koyarken, diğer taraftan da bu eski Sovyet ülkelerini kendine bağımlı kılacak alternatif enerji projelerinin de ortaya çıkmasına yol açmıştır. Ancak özellikle uluslararası şirketlerin söz konusu bölgede faaliyetlerinin artması ve yine AB’nin bu bölgeye stratejik ve ticari açıdan göstermiş olduğu ilgi Rusya ve AB arasında özellikle enerji merkezli gelişen bir jeopolitik çekişmenin de hüküm sürmesine yol açmıştır. 
Rusya ve $A B$ arasındaki bu jeopolitik çekişme daha çok siyasi entegrasyon ve enerji projeleri ile ilgili konularda kendini göstermektedir. AB’nin nüfuz alanını genişletme çabalarının karşısında Rusyảnın enerjiyi bir jeopolitik güç olarak kullanması ve bunun sonucunda Avrupa’nın enerji güvenliği ile ilgili kaygılarının artması AB’nin daha pragmatik projeler geliştirmesini tetiklemiştir. $\mathrm{AB}$ bu bağlamda enerji taşıma projelerini hem desteklemiş hem de geliştirmiştir. $\mathrm{Bu}$ projelerde, AB’ye geçen Rus enerjisinin transfer ülkesi durumunda olan Ukrayna’nın da büyük önemi bulunmaktadır. Başlattığı enerji transferi projelerini tam olarak tamamlayamamış olan $\mathrm{AB}$ hala Rusya'dan gelen gaza önemli ölçüde bağımlı bulunmaktadır. Son yaşanan Ukrayna krizi ile birlikte $\mathrm{AB}$ ortaya koyduğu yeni stratejileriyle bundan sonraki dönemde de daha pragmatik ve sert politikalar izleyeceğinin sinyallerini vermektedir.

Sonuç olarak, Hazar bölgesi $\mathrm{AB}$ ve Rusya'nın ekonomi-politik çekişme alanlarının başında gelmektedir ve bu çekişmelerin sadece ekonomik sonuçlarının ötesinde siyasi sonuçlarının gerek bölgesel gerekse de küresel çok daha büyük hasarlara yol açtığı Ukrayna krizleri ekseninde net bir şekilde kendini göstermektedir. Her iki aktörün bu bölgeye yönelik farklı bakış açıları, stratejileri ve amaçları bulunmaktadır ve her şeyden de önemlisi bu iki farklı "siyasi” bakışın birleştiği alanlar çakıştığı alanlardan çok daha azdır. Son Ukrayna krizinin her iki aktörü karşı karşıya getirdiği düşünüldüğ̈ünde gerek $\mathrm{AB}$ gerekse de Rusya’nın Hazar çekişmesinin gerçekte çok boyutlu ve oldukça derin olduğu gözlenmektedir. Bu son kriz sonrası her iki aktörün güven teşkil edecek yaklaşımlarda bulunması da zaman alacağı dikkate alınırsa Hazar’n bundan sonraki yıllarda her iki aktörün güç ve gövde gösterisine sıklıkla şahit olacağını tahmin etmek güç değildir. 


\section{Kaynakça}

Cain, Michael J. G., Rovshan Ibrahimov, Fevzi Bilgin (2012) "Linking the Caspian to Europe: Repercussions of the Trans-Anatolian Pipeline", Rethink Institute, no. 06

Chyong, Chi Kong (2014) "Why Europe Should Support Reform of the Ukrainian Gas Market - or Risk a Cut-Off”, European Council on Foreign Relations, no 113

Dağdemir, Elif Uçkan (2007) “Avrupa Birliği’nin Enerji Arz Güvenliği İçin Dış Enerji Politikası Arayışları”, Eskişehir Osmangazi Üniversitesi Sosyal Bilimler Dergisi, 8 (1)

de Micco, Pasquale (2014) "A Cold Winter to Come? The EU Seeks Alternatives to Russian Gas", European Parliament Directorate-General For External Policies

Dickel, Ralf, Elham Hassanzadeh, James Henderson, Anouk Honore, Laura El-Katiri, Simon Pirani, Howard Rogers, Jonathan Stern, Katja Yafimava (2014) "Reducing European Dependence on Russia: Distinguishing Natural Gas Security From Geopolitics”, The Oxfrod Institute for Energy Studies, NG 92

Dragneva, Rilka, Kataryna Wolczuk (2012) "Russia, The Eurasian Customs Union and the EU: Cooperation, Stagnation or Rivalry?", Chatham House Briefing Paper

Golovnin, Michail (2008) “Opportunuties and Obstacles to EurAsEC Integration”, EDB Eurasian Integration Yearbook 2008

Griffith, Brenth (1998) "Back Yard Politics: Russia’s Forein Policy Toward the Caspian”, Demokratizatsiya, vol. 6 , nu. 2: 426-441

Güney, Nurşin Ateşoğlu (2014) "Where does the EU Stand in Energy Dependence on Russia After the Ukrainian Crisis?”, Perceptions: Journal of International Affairs, cilt 19, sayı 3: 15-34

Hafner, Manfred (2014) “The Southern Gas Corridor and the EU Gas Security of Supply: What's Next?", Caspian Report, no. 8

İşeri, Emre (2014) “TANAP: '21. Yüzyllın projesi”, Al Jazeera Turk, 20.09.2014, http://www.aljazeera.com.tr/ gorus/tanap-21-yuzyilin-projesi

Karagöl, Erdal Tanas, Mehmet Kızılkaya (2015) “Rusya-AB-Türkiye üçgeninde Türk Akımı”, SETA Perspektif, sayı 105

Kazantsev, Andrei. (2008) "Russian Policy in Central Asia and the Caspian Sea Region", Europe-Asia Studies, vol. 60 , nu. 6: 1073-1088

Kirby, Paul (2014) "Russias Gas Fight with Ukraine”, BBC, 31.10.2014, http://www.bbc.com/news/worldeurope-29521564

Kramer, Andrew E. (2006) "Russia Cuts Off Gas to Ukraine in Cost Dispute", New York Times, 02.01.2006, http://www.nytimes.com/2006/01/02/international/europe/02russia.html?pagewanted=all\&_r=0

Kramer, Andrew E. (2009) "Russia Cuts Off Gas Deliveries to Ukraine", New York Times, 01.01.2009, http:// www.nytimes.com/2009/01/02/world/europe/02gazprom.html

Kusznir, Julia (2013) "TAP, Nabucco West, and South Stream: The Pipeline Dilemma in the Caspian Sea Basin and Its Consequences for the Development of the Southern Gas Corridor", Caucasus Analytical Digest, no. 47

Lehne, Stefan (2014) “Time to Reset the European Neihgborhood Policy", Carnegie Endowment, http:// carnegieendowment.org/files/time_reset_enp.pdf

Parfitt, Tom (2006) "Russia Turns Off Supplies to Ukraine in Payment Row, and EU Feels the Chill", Guardian, 02.01.2006, http://www.theguardian.com/world/2006/jan/02/russia.ukraine

Park, Jeanne (2014) “The European Union's Eastern Partnership”, Council on Foreign Relations, 14.03.2014, http://www.cfr.org/europe/european-unions-eastern-partnership/p32577 
Pirani, Simon, Jonathan Stern, Katja Yafimava (2009) “The Russo-Ukrainian gas dispute of January 2009: A Comprehensive Assessment", Oxford Institute for Energy Studies, NG 27

Pop, Valentina (2009) “EU expanding its 'sphere of influence,' Russia says", EUObserver, https://euobserver. com/foreign/27827

Ramesh, Kaavya (2014) “The Bear Unsheathes its Energy Weapon: The Russian Gas Cutoff”, Institute for Energy Research, 19.06.2014, http://instituteforenergyresearch.org/analysis/bear-unsheathesenergy-weapon-russian-gas-cutoff-u-s-can/

Raszewski, Slawomir (2010) “The EU's External Policy of Energy Diversification in the Wider Black (and Caspian) Sea Region: Regional Security Complex or Security Community?”, The Black Sea Region and EU Policy: The Challenge of Divergent Agendas (ed. Karen Henderson, Carol Weaver), Ashgate

Shi, Chunyang (2009) "Perspective on Natural Gas Crisis between Russia and Ukraine", CCSE Review of European Studies, cilt. 1, no. 1: 56-60

Uluatam, Ela (2010) “Nabucco Doğalgaz Boru Hattı Projesi Sürecinin Neresindeyiz?”, Ekonomik Forum

"Baku Initiative", European Commission Directorate-General Energy and Transport, http://ec.europa.eu/dgs/ energy_transport/international/regional/caspian/energy_en.htm

"Declaration: Prague Summit - Southern Corridor", 08.05.2009, http://eu-un.europa.eu/articles/en/ article_8715_en.htm

"European Energy Security Strategy", European Commission, 28.05.2014

“European Neighbourhood Policy (ENP)", European Union External Action, http://eeas.europa.eu/enp/ about-us/index_en.htm

"Eurosian Union Okays Free Trade With Iran", Press TV, 15.06.2015, http://www.presstv.ir/ Detail/2015/05/15/411131/Iran-eurasia-union-free-trade-russia

"Facts and figures about the Eastern Partners of the European Union", Eurostat Newsrelease, 89/2015, 20.05.2015

"FAQ on Eastern Partnership", Eastbook EU, (Son Erişim: 09.08.2015) http://eastbook.eu/en/faq-oneastern-partnership/\#one)

"Iran Plans to Sign Agreement With Euarasian Economic Union in 2015", Sputnik News, 27.01.2015, http:// sputniknews.com/politics/20150127/1017389100.html

"Joint Declaration of the Prague Eastern Partnership Summit", Council of the European Union, 7 Mayis 2009, http://www.consilium.europa.eu/uedocs/cms_data/docs/pressdata/en/er/107589.pdf

"Ministerial Declaration: Enhanced energy co-operation between the EU, the Littoral States of the Black and Caspian Seas and their neighbouring countries", 30.10.2006, s. 1-3 http://ec.europa.eu/dgs/ energy_transport/international/regional/caspian/doc/2006_11_30_astana_conclusions.pdf

"Q\&A: Ukraine gas row", BBC, 04.01.2006 (Son Erişim: 11.08.2015), http://news.bbc.co.uk/2/hi/ business/4569846.stm

“Russia, Kazakhstan, Belarus Sign Treaty Creating Economic Union”, RFERL, 29.05.2014, http://www.rferl. org/content/putin-in-astana-to-ink-eurasia-economic-union/25402319.html

"Second Strategic Energy Review: A EU Security and Solidarity Action Plan", 13.11.2008, http://www.aie.eu/ files/Directives_EU/strategic_energy_review_communication_EN.pdf

“TAP Project development schedule", http://www.tap-ag.com/the-pipeline/project-timeline\#21

"The Nabucco Gas Pipeline: A Chance for the EU to push for change in Turkmenistan", The Quaker Council for European Affairs, Aralık 2009 
